ARTICLE

\title{
The Human LL-37(17-29) antimicrobial peptide reveals a functional supramolecular structure
}

\author{
Yizhaq Engelberg ${ }^{1} \&$ Meytal Landau (i) ${ }^{1,2 凶}$
}

Here, we demonstrate the self-assembly of the antimicrobial human LL-37 active core (residues 17-29) into a protein fibril of densely packed helices. The surface of the fibril encompasses alternating hydrophobic and positively charged zigzagged belts, which likely underlie interactions with and subsequent disruption of negatively charged lipid bilayers, such

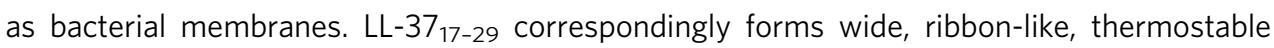
fibrils in solution, which co-localize with bacterial cells. Structure-guided mutagenesis analyses supports the role of self-assembly in antibacterial activity. LL-37 ${ }_{17-29}$ resembles, in sequence and in the ability to form amphipathic helical fibrils, the bacterial cytotoxic PSM $\alpha 3$ peptide that assembles into cross- $\alpha$ amyloid fibrils. This argues helical, self-assembling, basic building blocks across kingdoms of life and points to potential structural mimicry mechanisms. The findings expose a protein fibril which performs a biological activity, and offer a scaffold for functional and durable biomaterials for a wide range of medical and technological applications.

\footnotetext{
${ }^{1}$ Department of Biology, Technion-Israel Institute of Technology, 3200003 Haifa, Israel. ${ }^{2}$ Centre for Structural Systems Biology (CSSB), and European Molecular Biology Laboratory (EMBL), 22607 Hamburg, Germany. ${ }^{凶}$ email: mlandau@technion.ac.il
} 
$\mathrm{T}$ he assembly of basic biological molecules into filamentous structures provides ample opportunities to design bioinspired materials for medical and technological applications $^{1-8}$. One such application is addressing the urgent need to fight microbial aggressive, resistance, infections using materials which allow oral bioavailability, stability in harsh conditions, and long shelf-life. Antimicrobial peptides (AMPs) are canonical components of the innate immune system of many organisms 9 . AMP self-assembly bears functional relevance and can enhance antimicrobial activity ${ }^{10}$. Certain AMPs assemble into well-ordered fibrils that resemble amyloids ${ }^{11-14}$, which are proteins known to form cross- $\beta$ fibrils composed of tightly mated $\beta$-sheets, and have been associated with neurodegenerative and systemic diseases ${ }^{15,16}$. Correspondingly, recent evidence of antimicrobial properties among some human amyloids suggests a potential physiological role of proteins otherwise known as pathological ${ }^{17-21}$.

Our previous findings demonstrated cross- $\alpha$ amyloid fibrillation of the cytotoxic phenol-soluble modulin $\alpha 3$ (PSMa3) peptide secreted by the pathogenic bacterium Staphylococcus aureus ${ }^{22,23}$. These fibrils are composed entirely of $\alpha$-helices that stack perpendicular to the fibril axis into mated "sheets", just as the $\beta$ strands assemble in amyloid cross- $\beta$ fibrils ${ }^{24}$. PSMa3 is toxic to human cells, and some of its truncations and mutants show antibacterial activity ${ }^{25-27}$. Overall, PSM 3 3 provides a link between toxic activities against human and bacterial cells and unique helical amyloid fibrils 22,23 . Moreover, this architecture offers a scaffold for the design of various supramolecular nanostructures ${ }^{1,8}$. Although originating from different organisms, PSMa3 display sequence similarity with human LL-37 (hLL-37) (Supplementary Fig. 1), a hCAP-18 protein cleavage product which plays an important role in the first line of defense against pathogen ${ }^{28}$, which is also known to self-assemble ${ }^{29,30}$. Fibrillation of LL-37 was found critical for binding DNA and affecting receptors in the immune system ${ }^{31}$. Both PSMa 3 and hLL-37 are cleaved in vivo into active truncations with diverse activities ${ }^{32-36}$. Some hLL-37 fragments show a diverse array of selectivity against microbial strains, and additional functions within the immune system $^{34,37,38}$. Bacterial proteases can too cleave LL-37, supposedly for degradation or to release virulence factors ${ }^{36}$. Here we demonstrate that the active core peptide of hLL-37, containing residues 17-19 (hLL-37 17-29), formed supra-helical highly stable fibrils that interact with bacterial cells. Structure-guided mutagenesis supported a plausible active fibril arrangement.

\section{Results}

The antibacterial $\mathrm{LL} 7_{17-29}$ forms supra-helical fibrils. The hLL-37 ${ }_{17-29}$ fragment was suggested to serve as the active core of the AMP, showing a different spectrum of antibacterial activity as compared to the full-length protein and other fragments, including being the shortest LL-37 fragment retaining anti-viral activity ${ }^{36,39-41}$. Although not directly detected in vivo, hLL$37_{17-29}$ can be cleaved from hCAP-18 or LL-37 by either proteinase $\mathrm{K}$ or staphylococcal peptidase I on its $\mathrm{N}$-terminal side, and by trypsin on its C-terminal side. hLL-37 $7_{17-29}$ is also the region within hLL-37 showing the highest sequence similarity to PSMa3 (Supplementary Fig. 1), and like the latter, forms a helical monomeric structure shown by NMR experiments ${ }^{42}$. More specifically, hLL-37 ${ }_{17-29}$ generates an amphipathic helix with a larger hydrophobic moment compared to the entire hLL-37 and to PSMa3 (Supplementary Table 1). hLL-37 $7_{17-29}$ elicited dosedependent inhibition of Gram-positive Micrococcus luteus growth (Supplementary Fig. 2), with a minimal inhibitory concentration (MIC) ${ }^{43}$ of $22 \mu \mathrm{M}$ (Fig. 1). It was also active against the Staphylococcus hominis bacterium, with a MIC of $39 \mu \mathrm{M}$ (Supplementary Fig. 3).

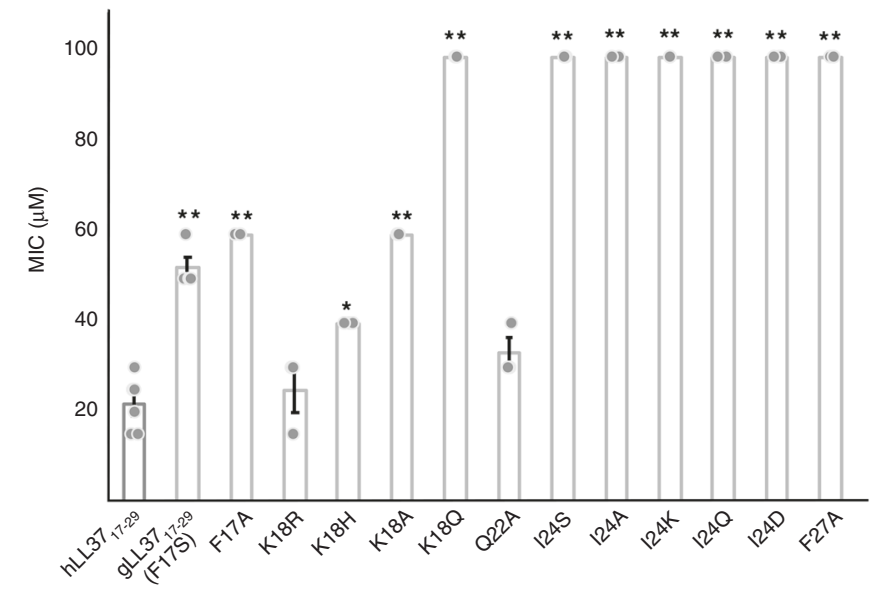

Fig. 1 The effect of LL-37 $7_{17-29}$ and its mutants on the growth of $M$. luteus. hLL-37 $17-29$ and single-point mutants were incubated with M. luteus for $24 \mathrm{~h}$ at a range of concentrations up to $100 \mu \mathrm{M}$, and bacterial growth rate was measured by optical density. From the resulting growth curves, the area under the curve (AUC) was calculated. MIC values were defined as the minimal concentration of the peptide which yielded less than $20 \%$ of the AUC of the control (bacteria with no added peptides). The mean MIC value of hLL-37 $17-29$ is $22 \mu \mathrm{M}$. Mean MIC values of the F17A and K18A mutants, substituting residues lining the central pore, are $60 \mu \mathrm{M}$. Similarly, the mean MIC value gLL-37 $7_{17-29}$ (equivalent to an F17S mutation) is $53 \mu \mathrm{M}$. The K18R, $\mathrm{K} 18 \mathrm{H}$ and $\mathrm{K} 18 \mathrm{Q}$ mutants showed mean MIC values of 25,40 , and $>100 \mu \mathrm{M}$, respectively. The Q22A mutation, substituting a residue showing minimal contacts with other residues within the fibrillar assembly, showed a mean MIC value of $33 \mu \mathrm{M}$. The I24A, 124S, 124K, I24D and I24Q mutations,

substituting a residue fully buried in the four-helix bundle, showed a mean MIC value of $>100 \mu \mathrm{M}$. The F27A mutation, substituting a buried residue contacting other residues within the four-helix bundle and on surrounding helices in the fibrillar assembly, showed a mean MIC value of $>100 \mu \mathrm{M}$. The experiments were performed at least three times, each on different days. Dots display measured values of individual repeats. Error bars indicate the standard error calculated between all measures. A $t$-test for two-sample assuming equal variances was performed, asterisk indicates $p<5 \times 10^{-03}$ and double asterisk indicates $p<5 \times 10^{-05}$, compared to hLL-37 $17-29$. Source data are provided as a Source data file.

We found that hLL-37 ${ }_{17-29}$ formed long (several micrometers and longer), ribbon-like, fibrils, visualized using transmission electron microscopy (TEM) (Fig. 2). Cryogenic electron microscopy (CryoEM) showed that the wide (few hundred nanometers) fibrils are composed of lateral association of thinner fibrils (Supplementary Fig. 4). The wide fibrils also formed in the presence, and interacted with M. luteus cells (Fig. 2). Our determination of the crystal structure of hLL-37 $17-29$ at $1.35 \AA$ resolution, revealed self-assembly of amphipathic helices into a densely packed and elongated hexameric structure forming a central pore (Table 1, Fig. 3 and Supplementary Movie 1). There were two helices in the asymmetric unit of the crystal, with $67 \%$ of their individual solvent accessible surface areas buried within the assembly, indicating compact packing. For comparison, in the PSMa3 cross-a structure, each helix is $62 \%$ buried in the fibril ${ }^{22}$. In contrast, structures of full-length LL-37, co-crystallized alone or with different lipids, resulted in different levels of assembly, including monomeric, dimeric, tetramers and fiber-like structure of oligomers ${ }^{44}$. The latter was observed when full-length LL-37 was co-crystallized with dodecyl phosphocholine (PDB ID 5NNT), showing a repetitive architecture of juxtaposed "headto-tail" amphipathic helices, with interactions mediated by detergent molecules ${ }^{44}$. This structure formed a much looser 
a

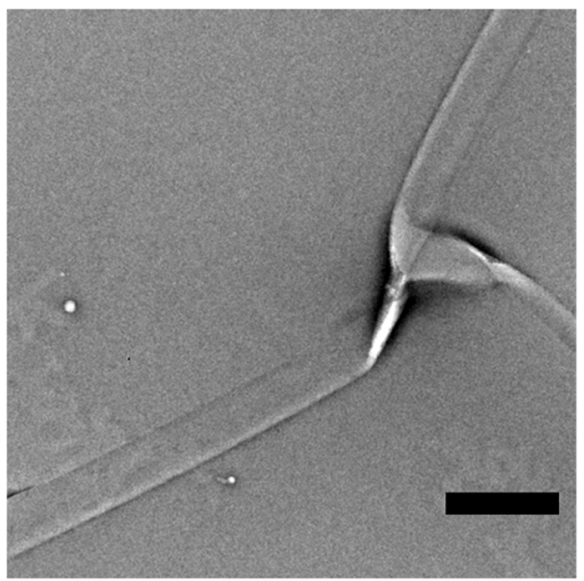

C

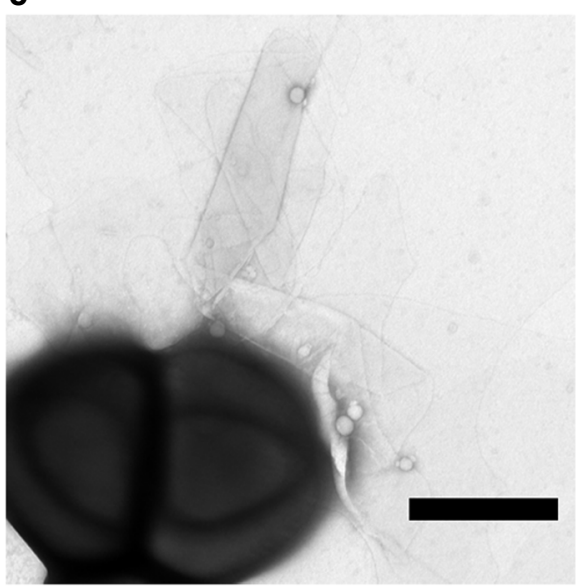

b

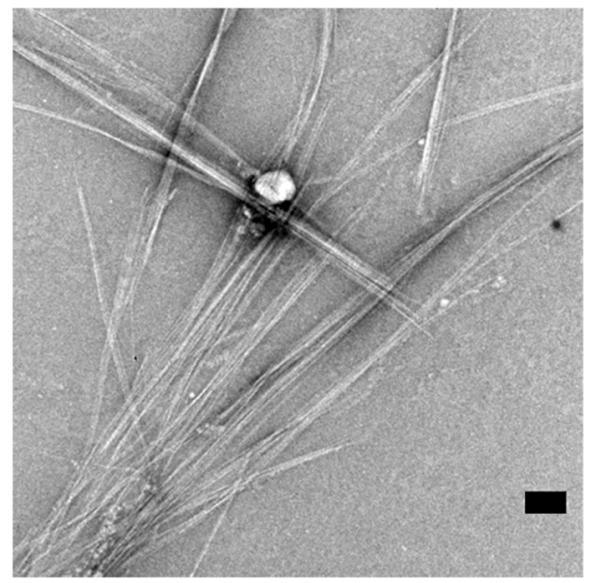

d

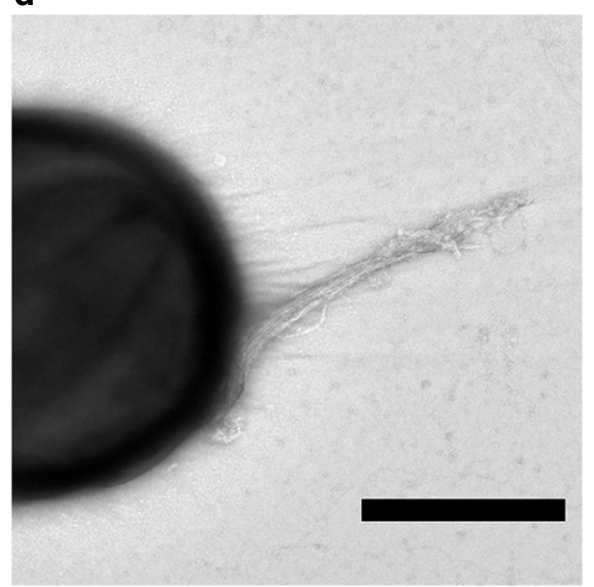

Fig. 2 Human and gorilla LL-37 $\mathbf{1 7 - 2 9}_{\mathbf{1 7}}$ fibrillar assemblies and interactions with bacteria. a An electron micrograph of 1 mM hLL-37 $17-29$ incubated for three days. b An electron micrograph of $1 \mathrm{mM}$ gLL-37 $17-29$ incubated for 3 days. c An electron micrograph of $30 \mu \mathrm{M}$ hLL-37 $17-29$ (close to the MIC concentration of $22 \mu \mathrm{M}$ ) incubated with $\mathrm{M}$. luteus for $4 \mathrm{~h}$. d An electron micrograph of $60 \mu \mathrm{M}$ gLL-37 $17-29$ (close to the MIC concentration of $53 \mu \mathrm{M}$ ), incubated with M. luteus for $4 \mathrm{~h}$. All scale bars represent $500 \mathrm{~nm}$.

packing compared to the LL-37 $17-29$ structure, with only $45 \%$ of the helix buried within the protein assembly. Overall, the generation of the hLL-37 $7_{17-29}$ active core allows antibacterial activity along with the formation of highly stable fibrils.

The structure of LL-37 $17-29$ lacked amyloid continuous sheets with individual molecules stacked perpendicular to the fibril axis, and correspondingly did not bind the amyloid indicator dye Thioflavin $\mathrm{T}$, in contrast to the cross- $\alpha$ amyloid fibrils of $\mathrm{PSMa}^{22}$ (Supplementary Fig. 5). Rather, the fibrillar assembly of LL-37 17-29 was comprised of associating four-helix bundles, each stabilized by a closely packed hydrophobic core (Fig. 3e, f). Arginine residues are lined on the surface of the bundles, with side chains extending outwards, providing an overall highly positively charged molecular electrical potential surface (Fig. 4). The interfaces between bundles comprises a network of polar interactions, including potential salt bridges between Asp26 and Arg23/Arg29 from two adjacent helices, and between Lys25 and the C-terminus of an adjacent helix (Fig. 5). Due to the symmetry in the structure, each bundle of four helices could form 16 interhelical polar interactions with adjacent helices in the assembly (Fig. 5). In addition, Asp26 could potentially form a salt bridge with Arg29 on the same helix. Such intra-helical salt-bridges are associated with increased $\alpha$-helical stability 45 . Phe27, facing towards another Phe27 residue from an adjacent helix, contributes to hydrophobic packing between bundles.
LL37 $_{17-29}$ fibrils are stable. The overall stable assembly of LL$37_{17-29}$, which includes a network of polar interactions and hydrophobic packing, corresponded with the thermostability of the fibrils, as visualized by electron micrographs after heating to 60 or $80^{\circ} \mathrm{C}$ (Fig. 6). Some disassembly at the edge of the wide fibrils, into thinner fibrils, could be observed after the $80^{\circ} \mathrm{C}$ heat shock, or after further incubation following the $60^{\circ} \mathrm{C}$ heat shock exposing a lateral fibril association. In comparison, collagen fibrils, which provides physical support to tissues, disintegrate upon heating to $65^{\circ} \mathrm{C}^{46}$. In addition, the surface charge and colloidal stability of the LL-37 $17-29$ were assessed using zeta potential measurements ${ }^{47}$, showing concentration dependent values, reaching $+25 \mathrm{mV}$ at $1 \mathrm{mM}$ (Supplementary Table 2). Congruently, other positively charged biological polymers were previously proposed for antimicrobials and drug delivery applications ${ }^{48,49}$.

LL37 $_{17-29}$ fibrils interact with bacterial cells. The fibrillar assembly in the crystal structure created alternating hydrophobic and polar (positively charged) zigzagged belts on its surface (Fig. 3d), suggesting interactions with and disruption of negatively charged lipid bilayers, such as bacterial membranes ${ }^{50}$. Confocal microscopy images of fluorescein isothiocyanate (FITC)-labeled hLL-37 17-29, which showed antibacterial activity similar to that of the unlabeled peptide (Supplementary Fig. 6), 


\begin{tabular}{|c|c|c|}
\hline & Gorilla LL-37 $17-29$ & Human LL-37 $17-29$ \\
\hline PDB accession code & $6 \mathrm{~S} 6 \mathrm{~N}$ & $6 \mathrm{~S} 6 \mathrm{M}$ \\
\hline Beamline & ESRF ID23-2 & EMBL P14 PETRA III \\
\hline Date & 12 May 2018 & 7 July 2018 \\
\hline \multicolumn{3}{|l|}{ Data collection } \\
\hline Space group & P 6122 & P 6122 \\
\hline \multicolumn{3}{|l|}{ Cell dimensions } \\
\hline$a, b, c(\AA)$ & 41.1541 .1557 .28 & 41.4541 .4557 .47 \\
\hline$\alpha, \beta, \gamma\left(^{\circ}\right)$ & 90.090 .0120 .0 & 90.090 .0120 .0 \\
\hline Wavelength $(\AA)$ & 0.873 & 0.976 \\
\hline Resolution $(\AA)$ & $57.3-1.1(1.13-1.10)$ & $\begin{array}{l}35.9-1.35 \\
(1.39-1.35)\end{array}$ \\
\hline R-factor observed (\%) & $5.6(55.2)$ & $5.6(78.8)$ \\
\hline$R_{\text {meas }}(\%)^{a}$ & $5.7(59.8)$ & $6.0(83.9)$ \\
\hline I / sigma & $31.1(3.1)$ & $21.5(3.5)$ \\
\hline Total reflections & $222293(5198)$ & $59815(4470)$ \\
\hline Unique reflections & $12186(808)$ & $6782(505)$ \\
\hline Completeness (\%) & $99.4(92.1)$ & $98.7(99.8)$ \\
\hline Redundancy & $18.2(6.4)$ & $8.8(8.9)$ \\
\hline $\mathrm{CC}_{1 / 2}(\%)^{\mathrm{b}}$ & $99.9(90.4)$ & $99.7(89.7)$ \\
\hline \multicolumn{3}{|l|}{ Refinement } \\
\hline Resolution $(\AA)$ & $35.6-1.1(1.13-1.10)$ & $\begin{array}{l}19.5-1.35 \\
(1.39-1.35)\end{array}$ \\
\hline Completeness (\%) & $99.4(92.1)$ & $98.7(99.8)$ \\
\hline No. reflections ${ }^{c}$ & $10967(727)$ & $6103(452)$ \\
\hline$R_{\text {work }}(\%)^{\mathrm{d}}$ & $16.0(47.8)$ & $23.2(39.9)$ \\
\hline$R_{\text {free }}(\%)$ & $17.9(55.9)$ & $26.8(39.2)$ \\
\hline No. atoms & 307 & 300 \\
\hline \multirow[t]{2}{*}{ Protein } & 123 (Chain A) & 122 (Chain A) \\
\hline & 128 (Chain B) & 147 (Chain B) \\
\hline Water & 56 & 31 \\
\hline \multicolumn{3}{|l|}{$B$-factors } \\
\hline \multirow[t]{2}{*}{ Protein } & 11.4 (Chain A) & $17.2($ Chain $A)$ \\
\hline & 10.5 (Chain B) & 16.3 (Chain B) \\
\hline Water & 28.8 & 28.1 \\
\hline \multicolumn{3}{|l|}{ R.m.s. deviations } \\
\hline Bond lengths ( $\AA$ ) & 0.014 & 0.011 \\
\hline Bond angles $\left({ }^{\circ}\right)$ & 1.708 & 1.613 \\
\hline Clash score 80 & 1.83 & 1.71 \\
\hline Molprobity score 80 & 0.94 & 0.92 \\
\hline Molprobity percentile 80 & 99th percentile & 99th percentile \\
\hline $\begin{array}{l}\text { Number of xtals used for } \\
\text { scaling }\end{array}$ & One crystals & One crystal \\
\hline
\end{tabular}

Values in parentheses are for highest-resolution shell.

a $R_{\text {is }}$ is redundancy-independent R-factor defined in ref. 81

${ }^{b} C_{\text {meas }} C_{1 / 2}$ is percentage of correlation between intensities from random half-datasets ${ }^{82}$.

${ }^{C} C_{1 / 2}$ is percentage of correlation between intensities
${ }^{C}$ Number of reflections corresponds to the working set.

${ }^{d} R_{\text {work }}$ corresponds to working set.

confirmed aggregation and co-localization of hLL-37 $17-29$ with bacterial cells (Supplementary Fig. 7 and Supplementary Movie 2).

Structure-guided mutagenesis supported functional fibrils. The role of the self-assembly in the antibacterial activity of hLL$37_{17-29}$ was examined using single-point mutations designed based on the solved crystal structure. Alanine substitution of Ile24, the most buried residue within the core of the four-helix bundle (Supplementary Fig. 8 and Supplementary Table 3), abolished antibacterial activity against M. luteus (Fig. 1) and against S. hominis (Supplementary Fig. 3). This mutation failed to exhibit peptide assembly around bacterial cells (Supplementary Fig. 9). Correspondingly, confocal microscopy images of the FITC-labeled I24A mutant, which, like the unlabeled peptide, was also ineffective against $M$. luteus (Supplementary Fig. 6), indicated absence of peptide aggregation (Supplementary Fig. 7). Likewise, the I24S, I24K, I24Q and I24D mutations all abolished antibacterial activity against $M$. luteus (Fig. 1), and confocal microscopy images of the FITC-labeled I24S inactive mutant (Supplementary Fig. 6) showed no detectable aggregation (Supplementary Fig. 7). Zeta potential measurements of the I24A inactive mutant showed significantly lower values compared to the native sequences, reaching only $+14 \mathrm{mV}$ at $1 \mathrm{mM}$ (Supplementary Table 2). Since I24A is a conservative substitution with no change in net charge, we attribute the lower zeta potential values to lack of an organized particle assembly by the mutant.

Phe27 is another residue significantly buried within the fibrillar assembly (Supplementary Table 3), forming contacts with residues on the four-helix bundle and with other helices in the fibrillar assembly (Supplementary Fig. 8). The F27A mutation abolished antibacterial activity against M. luteus (Fig. 1) and failed to aggregate when incubated with the bacteria (Supplementary Fig. 9). In contrast to the buried Ile24 and Phe27, Gln22 was the least buried residue in the assembly, forming minimal contacts within adjacent helices (Supplementary Fig. 8 and Supplementary Table 3). Consequently, the Q22A mutation resulted in minimal change in activity against $M$. luteus (a MIC of $33 \mu \mathrm{M}$; Fig. 1) and was also active against $S$. hominis, with a MIC of $53 \mu \mathrm{M}$ (Supplementary Fig. 3). Electron micrographs of the Q22A mutant showed large fibrous nanostructures contacting the bacterial cells (Supplementary Fig. 9). Correspondingly, confocal microscopy images of the FITC-labeled Q22A, which was slightly less active than the unlabeled Q22A peptide (Supplementary Fig. 6), formed aggregates which co-localized with the bacterial cells (Supplementary Fig. 7). Overall, the mutagenesis analyses indicated the importance of hLL-37 $7_{17-29}$ self-assembly in its antibacterial activity and in direct interactions with bacterial cells, and supported a plausible active fibril arrangement.

Investigation of the N-terminal residues which are not buried within the assembly (Supplementary Table 3) but which face the central pore, showed that the F17A and K18A mutants display a similar reduction in antibacterial activity against $M$. luteus, with a MIC of $60 \mu \mathrm{M}$ (Fig. 1). Maintaining the positive charge via a K18R substitution, showed a very similar MIC to that of hLL$37_{17-29}$, while the $\mathrm{K} 18 \mathrm{H}$ substitution showed slightly reduced activity (Fig. 1). In contrast, substitution to the polar but uncharged glutamine (K18Q) fully abolished activity (Fig. 1). The results suggest that the two residues facing the pore are important for activity, with the positive charge of Lys18 being the critical determinant. We therefore cannot conclude about the specific role of the central pore in activity, as the effect of substitutions might be related to the reduced positive charge ${ }^{51,52}$ regardless of its structural location.

Gorilla LL-37 $17-29$ showed a similar fibril architecture. The gorilla LL-37 (gLL-37) sequence contains two amino acid substitutions when compared to hLL-37, with one at position 17 , the first residue of LL-37 17-29, , substituting phenylalanine with serine (corresponding to a F17S mutation). gLL-37 17-29 exhibited slightly weaker antibacterial activity against $M$. luteus compared to hLL$37_{17-29}$, with a MIC of $53 \mu \mathrm{M}$ (Fig. 1), similar to the effect of the F17A mutant. The 1.1 A resolution crystal structure of gLL-37 17-29 displayed a similar assembly compared to hLL-37 17-29 (Table 1 and Fig. 7), with almost identical backbone positions and rootmean-square deviation (RMSD) of $0.15 \AA$, differing only in the two N-terminal positions that lined the central pore (Supplementary Fig. 10). Accordingly, both hLL-37 ${ }_{17-29}$ and gLL-37 $17-29$ formed wide fibrillary structures, as observed by cryogenic electron micrographs (Supplementary Fig. 4), and engaged in direct contact with M. luteus cells (Fig. 2). 


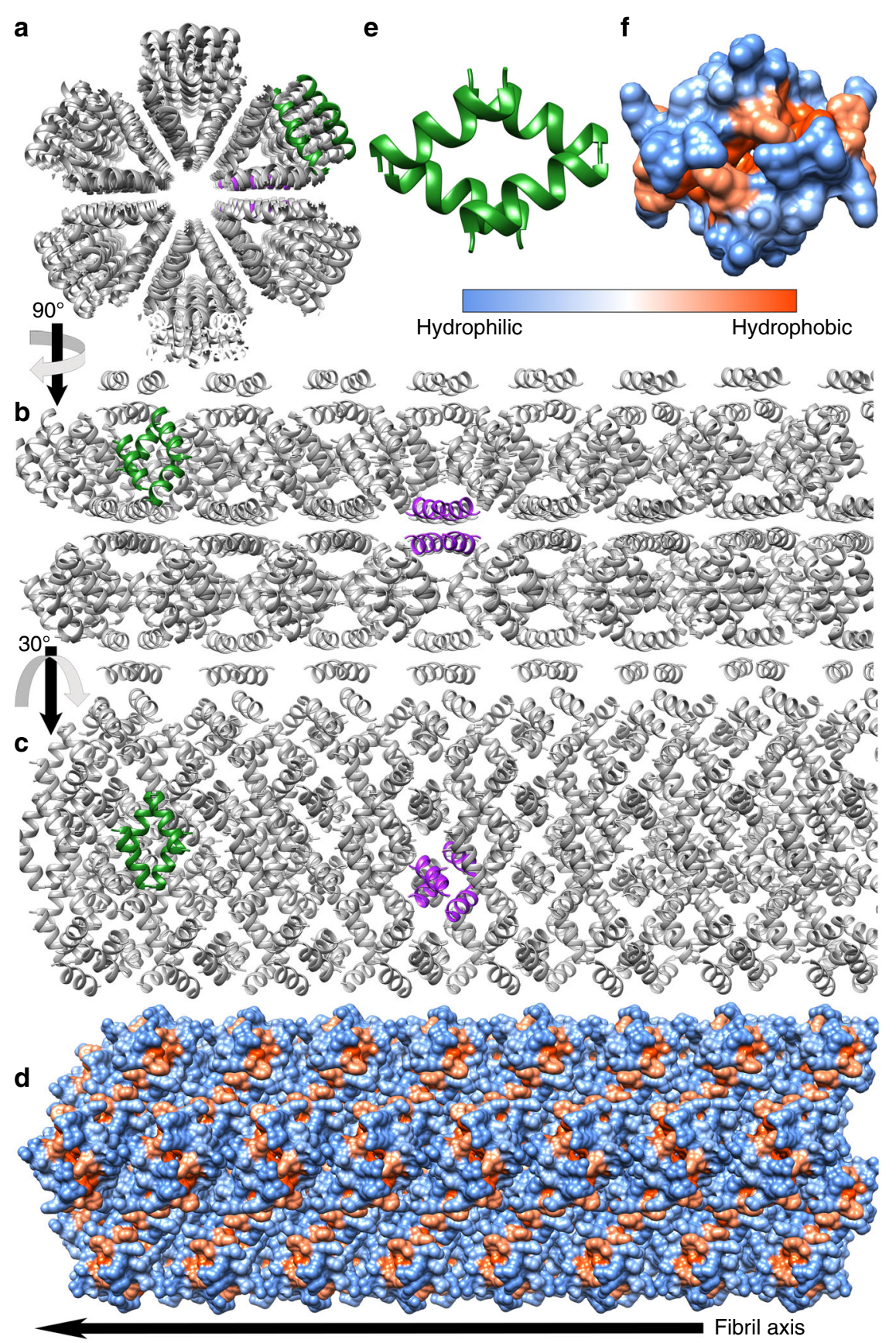

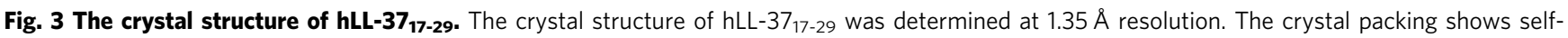
assembly of amphipathic helices into a densely packed, elongated hexameric fibril with a central pore. The fibril is composed of four-helix bundles with a hydrophobic core that associated via a network of polar interaction (Fig. 5). a The assembly is shown as grey ribbons, with two representative four-helix bundles colored green and purple to emphasize orientation in the fibril. $\mathbf{b}$ The view is rotated by $90^{\circ}$ in relation to panel a, showing the structure along the fibril axis. c The view is rotated by $30^{\circ}$ along the fibril axis compared to b. d The fibril, in the same orientation as in panel c, is shown in a surface representation, colored by hydrophobicity, according to the scale bar. e An isolated four-helix bundle shown as green ribbons. $\mathbf{f}$ The four-helix bundle, in the same orientation as in $\mathbf{e}$, shown in a surface representation colored by hydrophobicity, according to the scale bar.

\section{Discussion}

To conclude, the atomic structures of human and primate antibacterial LL-37 $7_{17-29}$ showed a functional supramolecular nanostructure of densely packed amphipathic helices. This assembly into stable fibrils with a surface forming hydrophobic/charged zigzagged belts can be used as scaffolds for wide-ranging applications in bio and nanotechnology, regenerative medicine and bioengineering ${ }^{53}$, with the invaluable advantage of an inherent antibacterial activity. Links between fibril formation and antimicrobial activity are accumulating ${ }^{11-14,17-21,54}$, and here, we provide atomic-level insight for such example. Further elucidation of the interplay between antimicrobial activity and fibril formation and morphology will aid the design of AMPs with enhanced potency, selectivity, stability, bioavailability, and shelf-life. Successful design of such functional nanostructures with tunable self-assembly might provide novel antibacterial therapeutics or coating of medical devices, and will may target other roles of AMPs in immunomodulation and in killing cancerous cells $9,10,42$.

The LL-37 17-29 structure differs from known helical fibrils such as the toxic cross- $\alpha$ amyloid fibrils of PSM $\alpha$, and from structural 
a

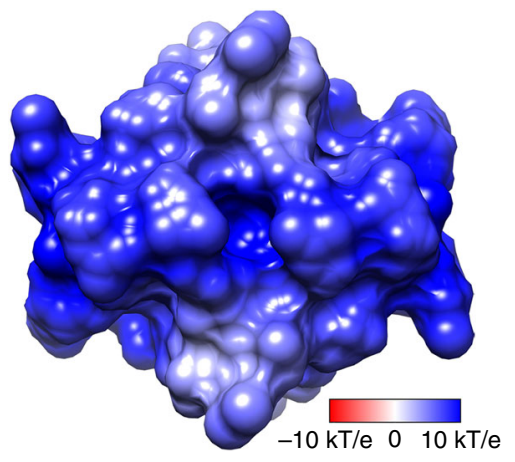

b

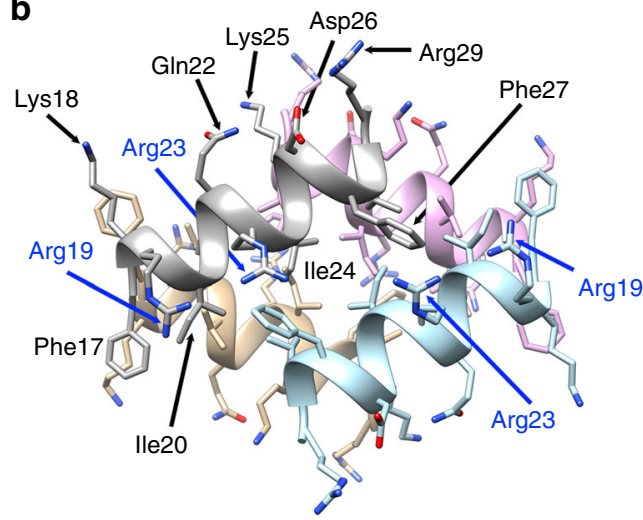

Fig. 4 Positively charged electrostatic surface of the four-helix bundle of hLL-37 17-29. a A projection of the electrostatic potential ( $\varphi$ ) onto the molecular surface of the four-helix bundle of hLL-37 $17-29$; the scale bar indicates $\varphi$ ranges between $-10 \mathrm{kT} / \mathrm{e}$ (dark red) and $10 \mathrm{kT} / \mathrm{e}$ (dark blue). $\mathbf{b}$ The bundle is displayed as ribbons, in the same orientation as in panel a, with side chains shown as sticks. The ribbons and carbons of each of the four helices are colored differently (gray, light blue, tan and pink) and non-carbon atoms are colored by atom type (oxygen in red and nitrogen in blue). Residues are labeled. Arg19 and Arg23 (labeled blue) from two helices lie across each side of the bundle.

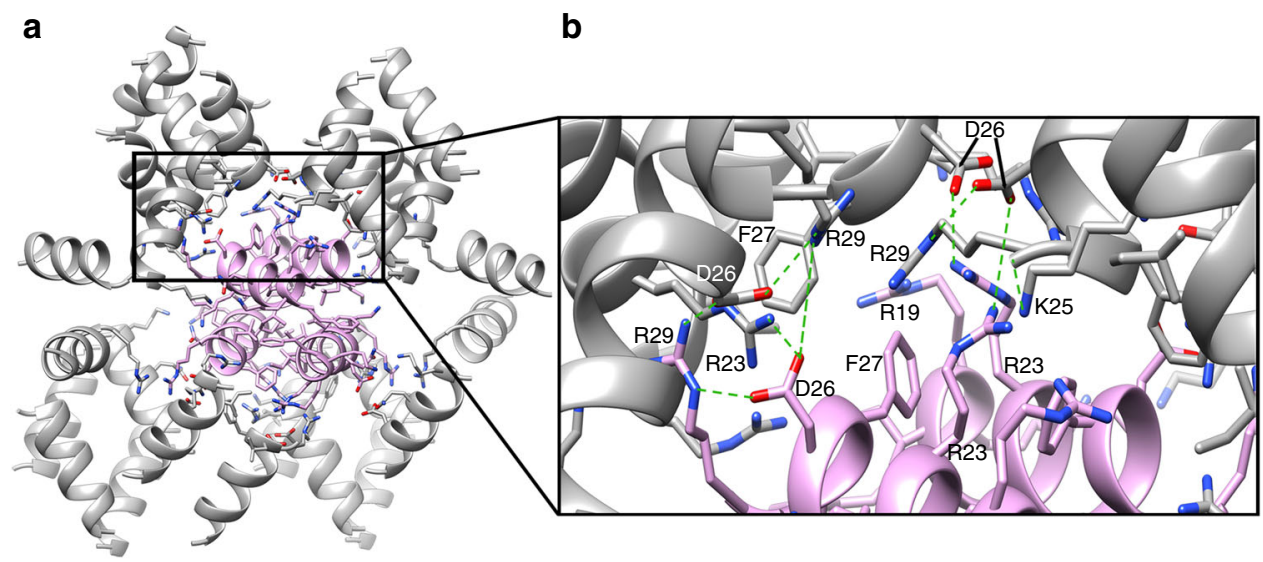

Fig. 5 Interfaces of the four-helix bundle with surrounding helices in the fibril assembly. a One representative four-helix bundle is shown by pink ribbons, and surrounding helices are colored grey. Side chains of the "pink" bundle and residues of surrounding helices which contact the bundle are shown as sticks, colored by atom type (oxygen in red and nitrogen in blue). The asymmetric unit of the crystal contains two chains which are almost identical (RMSD of $0.13 \AA$ ), thus, the bundle shows almost four identical interfaces. b A zoom-in view. Potential polar interactions (up to $4.3 \AA$ in distance) are indicated by green dotted lines: Asp26 can form inter-helical electrostatic interactions with Arg23 and with Arg29 from different helices, and intra-helical electrostatic interactions with Arg29. In addition, Lys25 can form electrostatic interactions with the negatively charged C-terminus of an adjacent helix. Overall, each helix shows four inter-helical and one intra-helical electrostatic interactions. In addition, Phe27 faces the middle of the interface, contributing to hydrophobic packing.

fibrils, such as collagen, actin, and fibrinogen. It overall presents a type of self-assembly which, to the best of our knowledge, is distinct from other protein fibrils, with a role in direct killing of bacterial cells still to be fully determined. Despite the different arrangement, the sequence similarity between the human LL-37 and the bacterial PSMa3, and their shared ability to form helical functional fibrils, suggest a possible molecular or structural mimicry mechanism used by the bacteria to provide immuneevasive and survival strategies ${ }^{55,56}$. This also points to potential functional building blocks across kingdoms of life in the form of densely packed amphipathic helical fibrils, complementing the exciting hypotheses about short amyloid peptides serving as prebiotic information-coding molecules ${ }^{57-59}$.

\section{Methods}

Peptides and reagents. LL37 $7_{17-29}$ sequences are derivatives of the human and gorilla cathelicidin antimicrobial peptides CAMP (UniProt IDs P49913 and Q1KLY3, respectively). hLL37 ${ }_{17-29}$, gLL37 $7_{17-29}$, their mutants, fluorescein isothiocyanate (FITC)-labeled peptides, and Staphylococcus aureus PSMa3 (UniProt ID H9BRQ7) were purchased from GL Biochem (Shanghai) Ltd. as lyophilized peptides, at $>98 \%$ purity. Thioflavin $\mathrm{T}$ (ThT) was purchased from Sigma-Aldrich. Ultra-pure double distilled water (UPddw) were purchased from Biological Industries. Additional reagents and consumable are mentioned below. Peptide sequences are shown in Supplementary Table 4.

Bacterial strains and culture media. Micrococcus luteus (M. luteus, an environmental isolate) was a kind gift from Prof. Charles Greenblatt from the Hebrew University of Jerusalem, Israel. An inoculum was grown in Luria-Bertani medium (LB), at $30^{\circ} \mathrm{C}, 220 \mathrm{rpm}$ shaking, $16 \mathrm{~h}^{27}$. Staphylococcus hominis (subsp. hominis Kloos and Schleifer S. hominis) was purchased from ATCC (ATCC ${ }^{\circledR} 27844^{\mathrm{mm}}$ ). An inoculum was grown in brain-heart infusion media (BHI), at $37^{\circ} \mathrm{C}, 220 \mathrm{rpm}$ shaking, $16 \mathrm{~h}$.

Determination of minimal inhibitory concentrations. M. luteus and S. hominis inoculums were diluted to an $\mathrm{OD}_{600}=0.1$. For the MIC experiments, LL37 $7_{17-29}$ and mutants were dissolved in PBS, and FITC-labeled peptides were dissolved in UPddw. The peptide stock solutions were then diluted into the bacterial media. Control and blank samples contained everything but peptides or everything but bacteria, respectively. Experiments were performed in a sterile 96-well plate and final reaction volume was $100 \mu \mathrm{l}$. Bacterial growth $\left(\mathrm{OD}_{595}\right)$ was measured during a $24 \mathrm{~h}$ incubation, at $30^{\circ} \mathrm{C}$, with $220 \mathrm{rpm}$ shaking, by a plate reader (FLUOstar omega or CLARIOstar, BMG LABTECH). Appropriate blanks were subtracted, and the area under the curve (AUC) was calculated ${ }^{60}$ from the resulting growth 
a

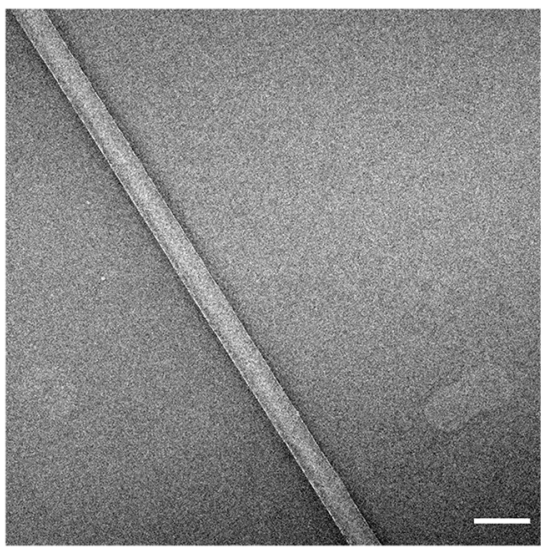

b

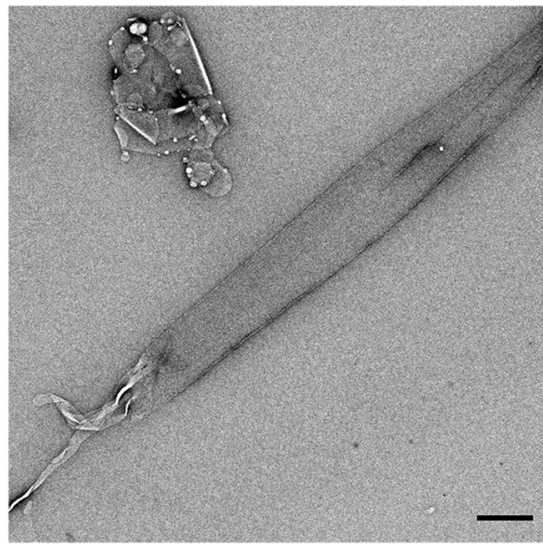

C

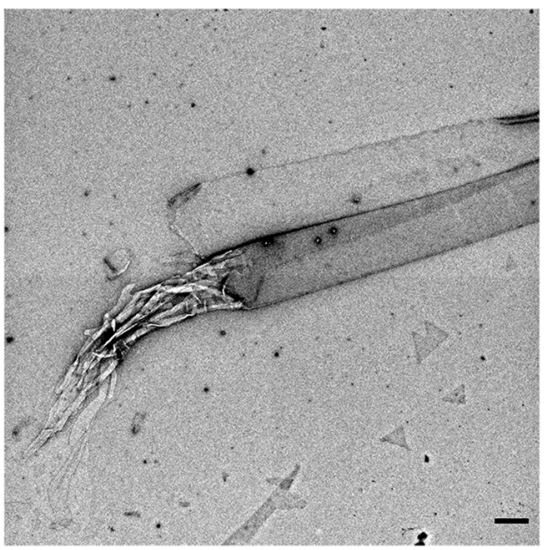

Fig. 6 Thermostability of hLL-37 $\mathbf{1 7 - 2 9}_{\mathbf{1}}$ fibrils. Transmission electron micrographs of $2 \mathrm{mM} \mathrm{LL-37} 7_{17-29}$ incubated for 3 days. a The sample was heated to $60^{\circ} \mathrm{C}$ for $10 \mathrm{~min}$. b The sample was incubated for additional $24 \mathrm{~h}$ at $37^{\circ} \mathrm{C}$ after the $60^{\circ} \mathrm{C}$ heat shock. $\mathbf{c}$ The sample was heated to $80^{\circ} \mathrm{C}$ for 10 min All scale bars represent $500 \mathrm{~nm}$.

a

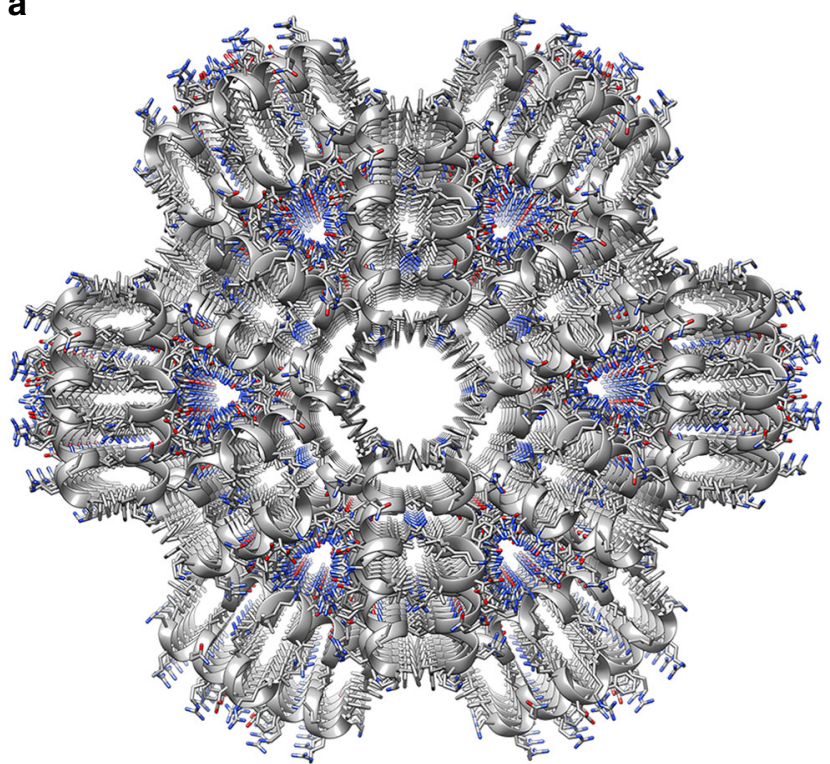

b

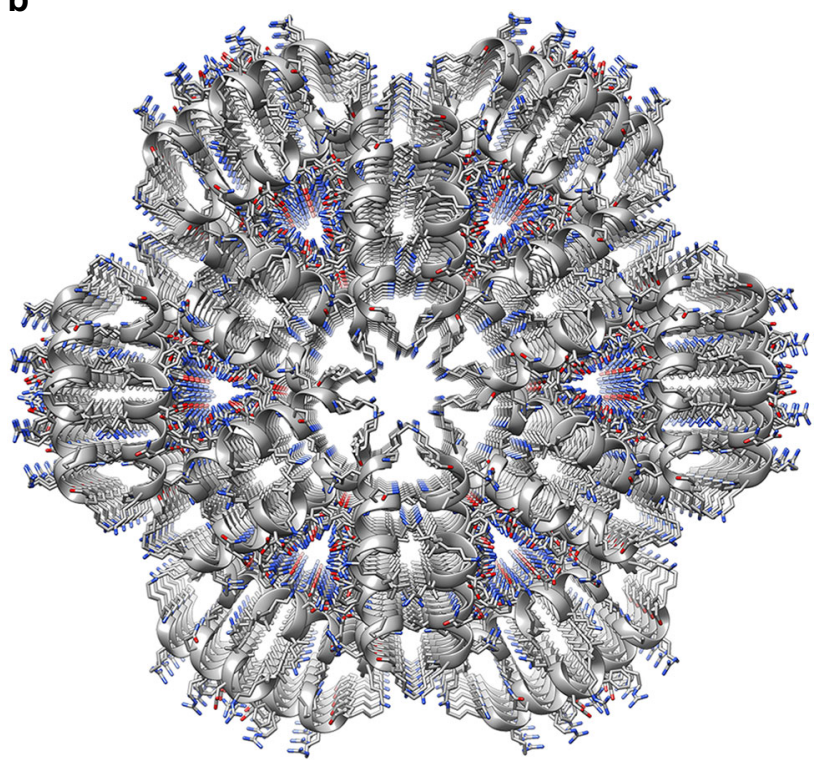

Fig. 7 Human and gorilla LL-37 $\mathbf{1 7 - 2 9}_{\mathbf{1}}$ share fibrillary architecture but differ in central pore properties. Comparison of human (a) and gorilla (b) LL-37 $17-29$ crystal structures, shown in grey ribbons with side chain shown as sticks colored by atom type (oxygen in red and nitrogen in blue). The view is down the fibril axis, showing the hexametric arrangement and the central pore. The overall structure of the two is highly similar (RMSD of $0.15 \AA$ for the asymmetric unit, comprising two helices and a similar space group and unit cell dimensions (Table 1)). The N-termini of the helices, with Phe17 in hLL-37 $17-29$ or Ser17 in $g L L-37_{17-29}$, and Lys18, line the central pore. The pore of $g L L-37_{17-29}$ is more occluded, due to the orientation of the lysine residues extending into the pore. In the hLL-37 $17-29$ structure, the lysine residues are almost perpendicular to the cross-section of the pore.

curves. MIC values were defined as the minimal concentration of the peptide which yielded less than $20 \%$ of the AUC of the control (bacteria with no added peptides). All experiments were performed in triplicates and were averaged. The entire experiment was repeated at least three times on different days, and the mean was calculated from the averaged triplicates of all biological repeats. Error bars represent standard errors of the mean. Two-tailed unpaired t-tests were performed to compare the mean MIC values of tested mutant peptides or derivatives to that of LL37 $_{17-29}$.

Confocal microscopy imaging of bacteria-peptide interaction. M. luteus were grown for $16 \mathrm{~h}$ and diluted to an $\mathrm{OD}_{600}=0.1$. FITC-labeled peptides were dissolved in UPddw, sonicated for $3 \mathrm{~min}$, and then added to the bacteria suspension to a final concentration of $30-150 \mu \mathrm{M}$ (as indicated in the relevant figure); final reaction volume was $100 \mu \mathrm{l}$. Control samples contained everything but the peptide or everything but the bacterium. All samples were incubated, in the dark, at $30^{\circ} \mathrm{C}$, with shaking at $220 \mathrm{rpm}$, for $4 \mathrm{~h}$. Thereafter, $1 \mathrm{ml}$ paraformaldehyde $4 \%$ (w/v in PBS) was placed over the samples, for $15 \mathrm{~min}$, at room temperature, in the dark. After fixation, samples were washed three times with fresh PBS, and then treated with Hoechst $33342(10 \mathrm{mg} / \mathrm{ml})$. All samples were applied to $\mu$-Slides VI 0.4 slides (Ibidi, 80666). Confocal images were acquired using an inverted confocal laserscanning microscope LSM 710 (Zeiss) equipped with a C-Apochromat 40× water immersion objective lens (NA 1.2) and a Definite Focus unit in an environmental chamber set at $37^{\circ} \mathrm{C}$. The laser wavelengths for excitation were $405 \mathrm{~nm}$ (Hoechst) and $488 \mathrm{~nm}$ (FITC). Brightfield images were collected from the $405 \mathrm{~nm}$ laser. Emission was collected sequentially at $410-497 \mathrm{~nm}$ for Hoechst and at $493-797 \mathrm{~nm}$ for FITC. The pinhole was set for $1 \mu \mathrm{m}$. Image processing was done with the Fiji software.

Time-lapse imaging: $M$. luteus bacteria from inoculum were diluted to $\mathrm{OD}_{600}=$ $0.1 \mathrm{in} \mathrm{LB}$. Hoechst $33342(10 \mathrm{mg} / \mathrm{ml})$ was added to bacteria suspension and incubated in the dark, for $10 \mathrm{~min}$, at room temperature. Just before imaging, FITCLL37 ${ }_{17-29}$ was added to the suspensions, to a final concentration of $30 \mu \mathrm{M}$. The samples were applied to $\mu$-Slides VI 0.4 slides. Images with a digital resolution of $2048 \times 2048$ pixels and 16-bit depth were acquired every $10 \mathrm{~min}$, at room temperature, using a Zeiss LSM 710 confocal microscope. Images were then used to construct a movie using Fiji software. A Gaussian filter $(\sigma=2.0)$ was applied to the FITC channel for noise removal and brightness and contrast of the images were adjusted $^{61-63}$ 
Thioflavin T fluorescence kinetic assay. Thioflavin $\mathrm{T}(\mathrm{ThT})$ powder was dissolved in UPddw to a stock solution of $2 \mathrm{mM}$, vortexed and filtered twice through a $0.22 \mu \mathrm{m}$ syringe-driven filter unit. Lyophilized PSM 3 peptide was pre-treated as previously described ${ }^{22}$ : PSM $\alpha 3$ was dissolved to $1 \mathrm{mg} / \mathrm{ml}$ in trifluoroacetic acid (TFA) and hexafluoroisopropanol (HFIP, $1: 1 \mathrm{v} / \mathrm{v}$ ), sonicated for $3 \mathrm{~min}$ in a sonication bath and left to air-dry in a chemical hood. Dried samples were stored at $-20^{\circ} \mathrm{C}$. Just before the experiment, PSM $\alpha 3$ was dissolved to $1 \mathrm{mM}$ in UPddw, sonicated for $3 \mathrm{~min}$ and immediately transferred to ice. Thereafter, it was diluted to $50 \mu \mathrm{M}$ with reaction buffer $(200 \mu \mathrm{M}$ ThT, $10 \mathrm{mM}$ sodium phosphate buffer, $\mathrm{pH}=$ 8 , and sodium chloride $150 \mathrm{mM}$ ), centrifuged at $12,500 \mathrm{rpm}$, for $10 \mathrm{~min}$, in a prechilled centrifuge $\left(4^{\circ} \mathrm{C}\right)$. Lyophilized LL37 $17-29$ peptide was dissolved in an identical reaction buffer to $1 \mathrm{mM}$. Blank solutions contained everything but the peptides. The reaction was carried out in a Greiner Bio-One black 96-well flat-bottom plate, immediately covered with a silicone sealing film (ThermalSeal RTS), and incubated in a plate reader (CLARIOstar or FLUOstar omega, BMG LABTECH) at $25^{\circ} \mathrm{C}$, with $220 \mathrm{rpm}$ shaking for $20 \mathrm{~s}$ before each measurement. ThT fluorescence (excitation: $438 \pm 20 \mathrm{~nm}$; emission: $490 \pm 20 \mathrm{~nm}$ ), was collected for at least $72 \mathrm{~h}$ (only $24 \mathrm{~h}$ are presented). All measurements were performed in triplicates and the entire experiment was repeated on at least three different days. Readings of blank solutions were subtracted. Error bars represent standard errors of the means.

Transmission electron microscopy. Lyophilized LL37 $17-29$ was dissolved in UPddw to a concentration of $1-5 \mathrm{mM}$ and incubated, at $37^{\circ} \mathrm{C}$, for several days, as indicated in the individual Figures. For imaging the peptides in the presence of bacterial cells, M. luteus was grown for $24 \mathrm{~h}$ in LB. Approximately $1.5 \times 10^{9}$ bacteria cells were washed three times with $10 \mathrm{mM}$ potassium phosphate buffer at $\mathrm{pH}=7.4$. Lyophilized peptides (LL37 $17-29$ and its mutants) were dissolved in this same buffer and added to the bacterial pellets, which were re-suspended to a final peptide concentration of 30-150 $\mu \mathrm{M}$ (as detailed in the relevant figures). Samples were then incubated, at $30^{\circ} \mathrm{C}$, with $220 \mathrm{rpm}$ shaking, for $4 \mathrm{~h}$. For testing Fibril thermostability, lyophilized hLL37 ${ }_{17-29}$ was dissolved to $2 \mathrm{mM}$ in UPddw and incubated at $37^{\circ} \mathrm{C}$ for 3 days. After incubation, samples were moved to a heat block, prewarmed to 60 or $80^{\circ} \mathrm{C}$ (as indicated in the relevant figure), for $10 \mathrm{~min}$. TEM samples were fixed on the EM grid directly from the heat block. The sample heated to $60^{\circ} \mathrm{C}$ was further incubated at $37^{\circ} \mathrm{C}$ for $24 \mathrm{~h}$ and then fixed on the grid.

TEM grid preparation and visualization were performed as follows. Samples (4-5 $\mu$ l) were applied directly onto glow-discharged (easiGlow; Pelco, Clovis, CA, USA, $15 \mathrm{~mA}$ current; negative charge; $25 \mathrm{~s}$ time) 400 mesh copper grids, with a grid hole size of $42 \mu \mathrm{m}$, stabilized with Formvar/carbon (Ted Pella, Inc.). Samples of peptide alone were allowed to adhere for $60 \mathrm{~s}$, and samples with M. luteus were allowed to adhere for $45 \mathrm{~s}$. Samples were than stained with $1 \%$ uranyl acetate solution (Electron Microscopy Science, 22400-1) for $60 \mathrm{~s}$ (peptide alone) or $30 \mathrm{~s}$ (peptide with M.luteus), before being blotted with Whatman filter paper. Specimens were examined with a FEI Tecnai T12 G2 electron microscope, at an accelerating voltage of $120 \mathrm{kV}$, or a FEI Tecnai G2 T20 electron microscope, at an accelerating voltage of $200 \mathrm{kV}$.

Cryogenic electron microscopy. Lyophilized human and gorilla LL37 $7_{17-29}$ were dissolved in UPddw to $1-5 \mathrm{mM}$ and incubated at $37^{\circ} \mathrm{C}$ for 3-10 days (as indicated in the relevant figures). Another sample was prepared from $2 \mathrm{mM} \mathrm{hLL37} 7_{17-29}$ dissolved in $2.7 \mathrm{mM}$ sodium dodecyl sulfate (SDS) (diluted in UPddw from a $40 \%$ stock). Of note, $2.7 \mathrm{mM}$ SDS is at sub critical micelle concentration (CMC). Within a temperature-controlled chamber at $100 \%$ relative humidity, $3 \mu \mathrm{l}$ of each sample were applied to a perforated carbon film supported by an electron microscope grid, which were pre-discharged, as described above. After $3 \mathrm{~s}$, the drop was blotted by Whatman filter paper and liquids were vitrified through rapid plunging of the grids into liquid ethane at its freezing point ${ }^{64}$. Specimens were examined under a FEI Talos $200 \mathrm{C}$ high-resolution electron microscope, at an accelerating voltage of $200 \mathrm{kV}$, using a Gatan 626 cryo-holder. To minimize electron beam radiation damage, the low-dose imaging mode was used. Images were collected digitally by a FEI Falcon III direct-imaging camera and the TIA software, with the help of the "phase plates" (FEI), to enhance image contrast ${ }^{65,66}$

Zeta potential measurements. Lyophilized LL37 ${ }_{17-29}$ and the I24A mutant were dissolved in UPddw and incubated at $0.01,0.1$, and $1 \mathrm{mM}$ concentrations at $37^{\circ} \mathrm{C}$ for $24 \mathrm{~h}$. Electrophoretic mobility measurements were performed in $25^{\circ} \mathrm{C}$ using a Malvern's Zetasizer Ultra device while samples were measured in folded capillary zeta cell zeta cuvettes (Malvern, DTS1070). Zeta potential was deduced using the Smoluchowski approximation ${ }^{47}$. The cells and the electrodes were washed with $\mathrm{ddw}$ three times before and after each sample. Device was equilibrated for $120 \mathrm{~s}$ before each sample and then three consecutive measurements were performed. The presented data is the mean of three consecutive measurements and standard deviation indicates the route mean square of the three measurements.

Crystallization conditions. Lyophilized human and gorilla LL37 $7_{17-29}$ peptides were dissolved to $10 \mathrm{mM}(17 \mathrm{mg} / \mathrm{ml})$ in double distilled water, vortexed and centrifuged at $14,000 \mathrm{rpm}, 4^{\circ} \mathrm{C}$, for $10 \mathrm{~min}$. hLL37 $7_{17-29}$ crystals were grown in a reservoir solution containing $0.2 \mathrm{M}$ sodium acetate, $0.1 \mathrm{M}$ Tris, $\mathrm{pH} 8.5$, and $30 \%(\mathrm{w} / \mathrm{v})$ polyethylene glycol 4000 . gLL37 $17-29$ crystals were grown in a reservoir solution containing $0.1 \mathrm{M}$ HEPES, $\mathrm{pH}=7.5$, and $1.4 \mathrm{M}$ sodium citrate. The crystals were grown at $20^{\circ} \mathrm{C}$, using the hanging-drop vapor diffusion technique. gLL37 $17-29$ crystals were soaked in cryo-protectant solution which contained reservoir solution, 5\% (v/v) 2-methyl-2,4-pentanediol (MPD) and 20\% glycerol. Crystals were flash-frozen in liquid nitrogen before X-ray data collection.

Structure determination and refinement. X-ray diffraction of gLL37 $17-29$ was collected at the ID23-EH2 micro-focus beamline at the European Synchrotron Radiation Facility (ESRF), Grenoble, France. The wavelength of data collection was $0.873 \AA$ A. X-ray diffraction of hLL37 $17-29$ was collected at the EMBL micro-focused beam P14, at the high brilliance 3rd Generation Synchrotron Radiation Source at DESY: PETRA III, Hamburg, Germany. The wavelength of data collection was $0.976 \AA$. Data indexing, integrating and scaling were performed using XDS and $\mathrm{XSCALE}^{67}$. Phases were obtained by molecular replacement using Phaser ${ }^{68}$. For the molecular replacement of gLL37 ${ }_{17-29}$, a 13-residue poly-alanine idealized helix was used as the search model. For the molecular replacement of hLL37 $7_{17-29}$, the structure of gLL37 $7_{17-29}$ was used as the search model. Crystallographic refinements were performed with Refmac $5^{69}$. Further model building was performed using $\operatorname{Coot}^{70}$ and illustrated with Chimera (including constructing Movie S1) ${ }^{71}$. The structures of human and gorilla LL37 $7_{17-29}$ were determined at $1.35 \AA$ and $1.1 \AA$ resolution, respectively. In both structures, there were two peptide chains in the asymmetric unit and water molecules. There were no residues detected in the disallowed region at the Ramachandran plot. Crystallographic statistics are presented in Table 1.

Sequence alignments and proteolytic digestion prediction. Sequence alignment between LL37 $17-29$ and PSMa3 was performed using the MAFFT server ${ }^{72}$. Amino acids are colored by their physicochemical properties ${ }^{73}$. Proteolytic digestion sites in the human LL37 were predicted using the Expasy's PeptideCutter Tool ${ }^{74}$.

Calculations of structural properties. The electrostatic potential map, hydrophobicity and B factor scales presented in the figures were created using Chimera ${ }^{71}$. The values of the hydrophobicity scale were according to Kyte and Doolittle ${ }^{75}$. The electrostatic potential was calculated using APBS-PDB2PQR ${ }^{76}$. Helix amphipathicity and the hydrophobic moment (Supplementary Table 1) were calculated with HeliQuest ${ }^{77}$.

Solvent-accessible surface area calculations. Solvent-accessible surface areas (SASAs) were calculated using AREAIMOL, with a probe radius of $1.4 \AA^{78,79}$, via the CCP4 package ${ }^{69}$. The solvent-accessible buried surface area of each chain in the asymmetric unit was calculated as the area difference between the isolated chain and the chain within the fibril assembly, and is presented as the percentage of the total SASA of the chain. The SASA per residue within different isolated helical assemblies are presented in Supplementary Table 3.

Reporting summary. Further information on research design is available in the Nature Research Reporting Summary linked to this article.

\section{Data availability}

Coordinates and structure factors for the X-ray crystal structures have been deposited in the protein data bank (PDB) with accession codes 6S6M (hLL37 $17-29$ ) and 6S6N (gLL37 $17-29$ ). Other data are available from the corresponding author upon reasonable request. Source data are provided with this paper.

Received: 7 June 2020; Accepted: 10 July 2020;

Published online: 04 August 2020

\section{References}

1. Bera, S. et al. Rigid helical-like assemblies from a self-aggregating tripeptide. Nat. Mater. 18, 503-509 (2019).

2. Wei, G. et al. Self-assembling peptide and protein amyloids: from structure to tailored function in nanotechnology. Chem. Soc. Rev. 46, 4661-4708 (2017).

3. Schnaider, L. et al. Self-assembling dipeptide antibacterial nanostructures with membrane disrupting activity. Nat. Commun. 8, 1365 (2017).

4. Mondal, S. et al. Formation of functional super-helical assemblies by constrained single heptad repeat. Nat. Commun. 6, 8615 (2015).

5. Cheng, R. P., Gellman, S. H. \& DeGrado, W. F. $\beta$-Peptides: from structure to function. Chem. Rev. 101, 3219-3232 (2001).

6. Kim, K. H. et al. Protein-directed self-assembly of a fullerene crystal. Nat. Commun. 7, 11429 (2016)

7. Grigoryan, G. et al. Computational design of virus-like protein assemblies on carbon nanotube surfaces. Science 332, 1071-1076 (2011) 
8. Zhang, S.-Q. et al. Designed peptides that assemble into cross- $\alpha$ amyloid-like structures. Nat. Chem. Biol. 14, 870-875 (2018).

9. Shai, Y. Mode of action of membrane active antimicrobial peptides. Biopolymers 66, 236-248 (2002).

10. Malekkhaiat Häffner, S. \& Malmsten, M. Influence of self-assembly on the performance of antimicrobial peptides. Curr. Opin. Colloid Interface Sci. 38, 56-79 (2018)

11. Jang, H. et al. Antimicrobial protegrin-1 forms amyloid-like fibrils with rapid kinetics suggesting a functional link. Biophys. J. 100, 1775-1783 (2011).

12. Zhao, H. et al. Interaction of the antimicrobial peptide pheromone Plantaricin A with model membranes: implications for a novel mechanism of action. Biochim. Biophys. Acta 1758, 1461-1474 (2006).

13. Auvynet, C. et al. Structural requirements for antimicrobial versus chemoattractant activities for dermaseptin S9. FEBS J. 275, 4134-4151 (2008).

14. Domanov, Y. A. \& Kinnunen, P. K. Antimicrobial peptides temporins B and L induce formation of tubular lipid protrusions from supported phospholipid bilayers. Biophys. J. 91, 4427-4439 (2006).

15. Dobson, C. M. Protein misfolding, evolution and disease. Trends Biochem. Sci. 24, 329-332 (1999)

16. Eisenberg, D. \& Jucker, M. The amyloid state of proteins in human diseases. Cell 148, 1188-1203 (2012).

17. Soscia, S. J. et al. The Alzheimer's disease-associated amyloid beta-protein is an antimicrobial peptide. PLoS ONE 5, e9505 (2010).

18. Kumar, D. K. et al. Amyloid-beta peptide protects against microbial infection in mouse and worm models of Alzheimer's disease. Sci. Transl. Med. 8, 340ra372 (2016)

19. Park, S. C. et al. Functional characterization of alpha-synuclein protein with antimicrobial activity. Biochem. Biophys. Res. Commun. 478, 924-928 (2016).

20. Hirakura, Y., Carreras, I., Sipe, J. D. \& Kagan, B. L. Channel formation by serum amyloid A: a potential mechanism for amyloid pathogenesis and host defense. Amyloid 9, 13-23 (2002).

21. Last, N. B. \& Miranker, A. D. Common mechanism unites membrane poration by amyloid and antimicrobial peptides. Proc. Natl Acad. Sci. USA 110, 6382-6387 (2013).

22. Tayeb-Fligelman, E. et al. The cytotoxic Staphylococcus aureus PSMalpha3 reveals a cross-alpha amyloid-like fibril. Science 355, 831-833 (2017).

23. Tayeb-Fligelman, E., Salinas, N., Tabachnikov, O. \& Landau, M. Staphylococcus aureus PSMalpha3 Cross-alpha fibril polymorphism and determinants of cytotoxicity. Structure 28, 301-313.e306 (2020).

24. Eisenberg, D. S. \& Sawaya, M. R. Structural studies of amyloid proteins at the molecular level. Annu Rev. Biochem. 86, 69-95 (2017).

25. Malishev, R. et al. Reciprocal interactions between membrane bilayers and S. aureus PSMalpha3 Cross-alpha amyloid fibrils account for species-specific cytotoxicity. J. Mol. Biol. 430, 1431-1441 (2018).

26. Cheung, G. Y. et al. Insight into structure-function relationship in phenolsoluble modulins using an alanine screen of the phenol-soluble modulin (PSM) alpha3 peptide. FASEB J. 28, 153-161 (2014).

27. Salinas, N., Colletier, J. P., Moshe, A. \& Landau, M. Extreme amyloid polymorphism in Staphylococcus aureus virulent PSMalpha peptides. Nat. Commun. 9, 3512 (2018).

28. Xhindoli, D. et al. The human cathelicidin LL-37-A pore-forming antibacterial peptide and host-cell modulator. Biochim. Biophys. Acta 1858 546-566 (2016).

29. Sood, R., Domanov, Y., Pietiainen, M., Kontinen, V. P. \& Kinnunen, P. K. Binding of LL-37 to model biomembranes: insight into target vs host cell recognition. Biochim. Biophys. Acta 1778, 983-996 (2008).

30. Shahmiri, M. et al. Membrane core-specific antimicrobial action of Cathelicidin LL-37 peptide switches between pore and nanofibre formation. Sci. Rep. 6, https://doi.org/10.1038/srep38184 (2016).

31. Lee, E. Y. et al. Helical antimicrobial peptides assemble into protofibril scaffolds that present ordered dsDNA to TLR9. Nat. Commun. 10, 1012 (2019)

32. Wang, G., Mishra, B., Epand, R. F. \& Epand, R. M. High-quality 3D structures shine light on antibacterial, anti-biofilm and antiviral activities of human cathelicidin LL-37 and its fragments. Biochim. Biophys. Acta 1838, 2160-2172 (2014).

33. Johansson, J., Gudmundsson, G. H., Rottenberg, M. E., Berndt, K. D. \& Agerberth, B. Conformation-dependent antibacterial activity of the naturally occurring human peptide LL-37. J. Biol. Chem. 273, 3718-3724 (1998).

34. Epand, R. F., Wang, G., Berno, B. \& Epand, R. M. Lipid segregation explains selective toxicity of a series of fragments derived from the human cathelicidin LL-37. Antimicrob. agents Chemother. 53, 3705-3714 (2009).

35. Deplanche, M. et al. Phenol-soluble modulin alpha induces G2/M phase transition delay in eukaryotic HeLa cells. FASEB J. 29, 1950-1959 (2015)

36. Wang, G. et al. Design of antimicrobial peptides: progress made with human Cathelicidin LL-37. Adv. Exp. Med Biol. 1117, 215-240 (2019).
37. Schmidtchen, A., Frick, I. M., Andersson, E., Tapper, H. \& Bjorck, L. Proteinases of common pathogenic bacteria degrade and inactivate the antibacterial peptide LL-37. Mol. Microbiol. 46, 157-168 (2002).

38. Chen, Z. et al. Design and antimicrobial activities of LL-37 derivatives inhibiting the formation of Streptococcus mutans biofilm. Chem. Biol. Drug Des. 93,1175-1185 (2019)

39. Rajasekaran, G., Kim, E. Y. \& Shin, S. Y. LL-37-derived membrane-active FK 13 analogs possessing cell selectivity, anti-biofilm activity and synergy with chloramphenicol and anti-inflammatory activity. Biochim. Biophys. Biomembr. 1859, 722-733 (2017)

40. Yamasaki, K. et al. Kallikrein-mediated proteolysis regulates the antimicrobial effects of cathelicidins in skin. FASEB J. 20, 2068-2080 (2006)

41. Murakami, M., Lopez-Garcia, B., Braff, M., Dorschner, R. A. \& Gallo, R. L. Postsecretory processing generates multiple cathelicidins for enhanced topical antimicrobial defense. J. Immunol. 172, 3070-3077 (2004).

42. Li, X., Li, Y., Han, H., Miller, D. W. \& Wang, G. Solution structures of human LL-37 fragments and NMR-based identification of a minimal membranetargeting antimicrobial and anticancer region. J. Am. Chem. Soc. 128, 5776-5785 (2006)

43. Schuurmans, J. M., Hayali, A. S. N., Koenders, B. B. \& ter Kuile, B. H. Variations in MIC value caused by differences in experimental protocol. J. Microbiol. Methods 79, 44-47 (2009).

44. Sancho-Vaello, E. et al. Structural remodeling and oligomerization of human cathelicidin on membranes suggest fibril-like structures as active species. Sci. Rep. 7, 15371 (2017).

45. Kumar, S. \& Nussinov, R. Close-range electrostatic interactions in proteins. Chembiochem 3, 604-617 (2002).

46. Bigi, A., Cojazzi, G., Roveri, N. \& Koch, M. H. J. Differential scanning calorimetry and X-ray diffraction study of tendon collagen thermal denaturation. Int. J. Biol. Macromol. 9, 363-367 (1987).

47. Bhattacharjee, S. DLS and zeta potential - What they are and what they are not? J. Control Release 235, 337-351 (2016).

48. Tamara, F. R., Lin, C., Mi, F.-L. \& Ho, Y.-C. Antibacterial effects of Chitosan/ Cationic peptide nanoparticles. Nanomaterials (Basel) 8, 88 (2018)

49. Sydow, S., Aniol, A., Hadler, C. \& Menzel, H. Chitosan-Azide nanoparticle coating as a degradation barrier in multilayered polyelectrolyte drug delivery systems. Biomolecules 9, 573 (2019).

50. Papo, N. \& Shai, Y. Can we predict biological activity of antimicrobial peptides from their interactions with model phospholipid membranes? Peptides 24, 1693-1703 (2003)

51. Yin, L. M., Edwards, M. A., Li, J., Yip, C. M. \& Deber, C. M. Roles of hydrophobicity and charge distribution of cationic antimicrobial peptides in peptide-membrane interactions. J. Biol. Chem. 287, 7738-7745 (2012).

52. Nagaoka, I. et al. Augmentation of the lipopolysaccharide-neutralizing activities of human cathelicidin CAP18/LL-37-derived antimicrobial peptides by replacement with hydrophobic and cationic amino acid residues. Clin. Diagn. Lab Immunol. 9, 972-982 (2002).

53. Hughes, S. A. et al. Ambidextrous helical nanotubes from self-assembly of designed helical hairpin motifs. Proc. Natl Acad. Sci. USA 116, 14456-14464 (2019).

54. Kagan, B. L. et al. Antimicrobial properties of amyloid peptides. Mol. Pharm. 9, 708-717 (2012)

55. Friedland, R. P. Mechanisms of molecular mimicry involving the microbiota in neurodegeneration. J. Alzheimers Dis. 45, 349-362 (2015).

56. Landau, M. Mimicking cross-alpha amyloids. Nat. Chem. Biol. 14, 833-834 (2018).

57. Rout, S. K., Friedmann, M. P., Riek, R. \& Greenwald, J. A prebiotic templatedirected peptide synthesis based on amyloids. Nat. Commun. 9, 234 (2018).

58. Al-Garawi, Z. S. et al. The amyloid architecture provides a scaffold for enzyme-like catalysts. Nanoscale 9, 10773-10783 (2017)

59. Carny, O. \& Gazit, E. A model for the role of short self-assembled peptides in the very early stages of the origin of life. FASEB J. 19, 1051-1055 (2005).

60. Nawangsih, A. A., Damayanti, I., Wiyono, S. \& Kartika, J. G. Selection and characterization of endophytic bacteria as biocontrol agents of tomato bacterial wilt disease. Hayati J. Biosci. 18, 66-70 (2011)

61. Wegel, E. et al. Imaging cellular structures in super-resolution with SIM STED and localisation microscopy: a practical comparison. Sci. Rep. 6, 27290 (2016).

62. Cardinale, J. Histogram-based background subtractor for ImageJ. (ETH Zurich, Switzerland, 2010)

63. Gedraite, E. o. S. \& Hadad, M. in Proc. ELMAR-2011, 393-396 (IEEE, 2011)

64. Zhang, Y., Schmidt, J., Talmon, Y. \& Zakin, J. L. Co-solvent effects on drag reduction, rheological properties and micelle microstructures of cationic surfactants. J. Colloid Interface Sci. 286, 696-709 (2005).

65. Kaneko, Y., Danev, R., Nitta, K. \& Nagayama, K. In vivo subcellular ultrastructures recognized with Hilbert differential contrast transmission electron microscopy. J. Electron Microsc. (Tokyo) 54, 79-84 (2005). 
66. Tosaka, M., Danev, R. \& Nagayama, K. Application of phase contrast transmission microscopic methods to polymer materials. Macromolecules 38, 7884-7886 (2005).

67. Kabsch, W. XDS. Acta Crystallogr. D. Biol. Crystallogr 66, 125-132 (2010)

68. McCoy, A. J. et al. Phaser crystallographic software. J. Appl. Crystallogr. 40 658-674 (2007).

69. Winn, M. D. et al. Overview of the CCP4 suite and current developments. Acta Crystallogr D. Biol. Crystallogr 67, 235-242 (2011).

70. Emsley, P. \& Cowtan, K. Coot: model-building tools for molecular graphics. Acta Crystallogr. D. Biol. Crystallogr. 60, 2126-2132 (2004).

71. Pettersen, E. F. et al. UCSF Chimera-a visualization system for exploratory research and analysis. J. Comput. Chem. 25, 1605-1612 (2004).

72. Rozewicki, J., Li, S., Amada, K. M., Standley, D. M. \& Katoh, K. MAFFTDASH: integrated protein sequence and structural alignment. Nucleic Acids Res. 47, W5-W10 (2019).

73. Livingstone, C. D. \& Barton, G. J. Protein sequence alignments: a strategy for the hierarchical analysis of residue conservation. Comput. Appl. Biosci. 9, 745-756 (1993).

74. Gasteiger, E. et al. in The proteomics protocols handbook, 571-607 (Springer, 2005).

75. Kyte, J. \& Doolittle, R. F. A simple method for displaying the hydropathic character of a protein. J. Mol. Biol. 157, 105-132 (1982).

76. Jurrus, E. et al. Improvements to the APBS biomolecular solvation software suite. Protein Sci. 27, 112-128 (2018).

77. Gautier, R., Douguet, D., Antonny, B. \& Drin, G. HELIQUEST: a web server to screen sequences with specific alpha-helical properties. Bioinformatics 24, 2101-2102 (2008).

78. Lee, B. \& Richards, F. M. The interpretation of protein structures: estimation of static accessibility. J. Mol. Biol. 55, 379-400 (1971).

79. Saff, E. B. \& Kuijlaars, A. B. Distributing many points on a sphere. Math Intell. 19, 5-11 (1997).

80. Chen, V. B. et al. MolProbity: all-atom structure validation for macromolecular crystallography. Acta Crystallogr. D. Biol. Crystallogr 66, 12-21 (2010)

81. Diederichs, K. \& Karplus, P. A. Improved R-factors for diffraction data analysis in macromolecular crystallography. Nat. Struct. Biol. 4, 269-275 (1997).

82. Karplus, P. A. \& Diederichs, K. Linking crystallographic model and data quality. Science 336, 1030-1033 (2012).

\section{Acknowledgements}

We are grateful for Duilio Cascio (University of California Los Angeles) for advice and help with crystal structure determination. We thank Einat Netzer for help in conducting experiments, Carolin Seuring for advice on microscopy images, and Eilon Barnea, Nir Salinas and Yael Pazy-Benhar for commenting on the manuscript. We acknowledge guidance and technical support provided by Yael Pazy-Benhar and Dikla Hiya at the Technion Center for Structural Biology (TCSB), Na'ama Koifman and Ellina Kesselman from the Russell Berrie Electron Microscopy Center of Soft Matter, Yael Lupo-Haber and
Nitsan Dahan from the Life Science and Engineering Infrastructure Center, all at the Technion, Israel. This research was supported by Israel Science Foundation (grant no. 560/16), Israel Ministry of Science, Technology \& Space (grant no. 78567), U.S.-Israel Binational Science Foundation (grant no. 2017280), BioStruct-X, funded by FP7, and the iNEXT consortium of Instruct-ERIC. The synchrotron MX data collection experiments were performed at beamlines ID23-EH2 at the European Synchrotron Radiation Facility (ESRF), Grenoble, France, and at beamline P14, operated by EMBL Hamburg at the PETRA III storage ring (DESY, Hamburg, Germany). We are grateful to the teams at ESRF and EMBL Hamburg. We would like to thank Thomas R. Schneider and Gleb Bourenkov for their assistance in operating the P14 beamline.

\section{Author contributions}

Y.E. and M.L. conceived the presented idea. Y.E. conceived, designed and conducted the experiments. Y.E. and M.L. determined the crystal structures and wrote the paper.

\section{Competing interests}

The authors declare no competing interests.

\section{Additional information}

Supplementary information is available for this paper at https://doi.org/10.1038/s41467 020-17736-x.

Correspondence and requests for materials should be addressed to M.L.

Peer review information Nature Communications thanks the anonymous reviewer(s) for their contribution to the peer review of this work.

Reprints and permission information is available at http://www.nature.com/reprints

Publisher's note Springer Nature remains neutral with regard to jurisdictional claims in published maps and institutional affiliations.

c) (1) Open Access This article is licensed under a Creative Common Attribution 4.0 International License, which permits use, sharing, adaptation, distribution and reproduction in any medium or format, as long as you give appropriate credit to the original author(s) and the source, provide a link to the Creative Commons license, and indicate if changes were made. The images or other third party material in this article are included in the article's Creative Commons license, unless indicated otherwise in a credit line to the material. If material is not included in the article's Creative Commons license and your intended use is not permitted by statutory regulation or exceeds the permitted use, you will need to obtain permission directly from the copyright holder. To view a copy of this license, visit http://creativecommons.org/ licenses/by/4.0/.

(C) The Author(s) 2020 